\title{
A INTER-RELAÇÃO ENTRE A ESTATÍSTICA E A PROBABILIDADE: UM ESTUDO SOBRE OS CONHECIMENTOS DE PROFESSORES DE MATEMÁTICA DO ENSINO MÉDIO SOBRE A CURVA NORMAL
}

\author{
THE INTER-RELATIONSHIP BETWEEN STATISTICS AND PROBABILITY: \\ A STUDY ON THE TEACHERS KNOWLEDGE OF MIDDLE SCHOOL \\ MATHEMATICS ON THE NORMAL CURVE
}

\author{
André Fellipe Queiroz Araújo ${ }^{1}$ \\ José Ivanildo Felisberto de Carvalho ${ }^{2}$
}

\begin{abstract}
Resumo: No presente texto, são discutidos os resultados parciais de um estudo que propõe uma investigação sobre os conhecimentos didático-matemáticos de professores de Matemática do Ensino Médio relativos à relação mútua entre a Estatística e a Probabilidade por meio da Curva Normal. Para tanto, esse estudo está fundamentado no modelo teórico de Conhecimentos e Competências Didático-Matemáticos do professor - CCDM, desenvolvido no âmbito da teoria do Enfoque Ontossemiótico. Apresentaremos aqui uma discussão sobre os conhecimentos de três professores de Matemática do Ensino Médio da rede pública da Educação Básica do estado de Pernambuco. A coleta de dados consistiu na aplicação de um questionário diagnóstico composto por seis questões. Os resultados apontam que os professores apresentam lacunas sobre os conhecimentos matemáticos e didáticos para o trabalho com a Curva Normal nesta etapa de escolaridade, na perspectiva de uma mobilização articulada entre os conceitos estatísticos e probabilísticos abarcados por esse modelo matemático.
\end{abstract}

Palavras-chave: Estatística; Probabilidade; Curva Normal; Conhecimentos e Competências DidáticoMatemáticas; Formação de Professores.

\begin{abstract}
In the present text, we discuss the partial results of a study that proposes an investigation on the didactic-mathematical knowledge of teachers of Mathematics of Secondary Education relative to the mutual relation between Statistic and Probability through the Normal Curve. Therefore, this study is based on the theoretical model of knowledge and competences Didactic-Mathematics of the teacher - CCDM developed within the scope of Ontossemiotic Approach theory. We will present here a discussion about the knowledge of three teachers of Mathematics of the High School of the public network of Basic Education of the state of Pernambuco. Data collection consisted of the application of a diagnostic questionnaire composed of six questions. The results show that teachers present incipient mathematical and didactic knowledge to work with the normal curve in this stage of schooling, in the perspective of an articulated mobilization between the statistical and probabilistic concepts covered by this mathematical model.
\end{abstract}

Keywords: Statistic; Probability; Normal Curve; Knowledge and Skills Didactic-Mathematics; Teacher training.

\footnotetext{
${ }^{1}$ Especialista em Educação Matemática pela Universidade Cândido Mendes (UCAM). Mestrando em Educação Matemática e Tecnológica pela Universidade Federal de Pernambuco (UFPE), Recife, Pernambuco, Brasil. E-mail: andrefellipe93@ hotmail.com

2 Doutor em Educação Matemática pela Universidade Anhanguera de São Paulo, (UNIAN). Professor Adjunto da Universidade Federal de Pernambuco (UFPE), Recife, Pernambuco, Brasil. E-mail: ivanfcar@hotmail.com
} 


\section{Introdução}

Diariamente, por diversos meios de comunicação, deparamo-nos com uma gama de dados e informações estatísticas e probabilísticas sobre diferentes aspectos que permeiam nossa sociedade. Isso faz notarmos que a Estatística e a Probabilidade se constituem fundamentalmente como áreas de conhecimento que exercem um relevante papel em nossa vida cotidiana. Ambas subsidiam diversos tipos de estudos e pesquisas científicas e, além disso, o conhecimento que as permeiam é essencial para o desenvolvimento de habilidades, reflexões e o senso crítico, propiciando a formação de cidadãos capazes de interpretar e compreender uma variedade de fenômenos, dados e informações, além de tomar decisões e fazer previsões que influenciam na sua vida pessoal e social.

Nesse sentido, torna-se necessário que a escola, enquanto instituição de ensino, favoreça a formação de conceitos estatísticos e probabilísticos, tendo em vista que, para o estudante entender o mundo que o cerca, é preciso compreender os diferentes significados e representações desses conceitos, inseridos em diferentes contextos e situações (VERGNAUD, 1993).

Lopes (2008) destaca a importância da inserção do ensino da Estatística e da Probabilidade na Educação Básica, ao citar a constante necessidade de leitura e interpretação de dados estatísticos em muitas profissões e na vida cotidiana das pessoas, bem como o importante papel do raciocínio probabilístico na tomada de decisões.

A Base Nacional Curricular Comum (2017, 2018), por sua vez, orienta que o processo de ensino e aprendizagem da Estatística e da Probabilidade deve ser iniciado já nos primeiros anos do Ensino Fundamental e aprimorado e ampliado no Ensino Médio da escolarização básica. Esse documento, em linhas gerais, destaca a necessidade da abordagem de conceitos, fatos e procedimentos relativos a essas áreas de conhecimentos que estão presentes em muitas situações-problema do nosso cotidiano.

Entretanto, ainda com relação ao processo de ensino e aprendizagem da Estatística e da Probabilidade na Educação Básica, alguns estudos apontam algumas lacunas nesse processo. Guimarães et al., (2009), Silva (2015) e Batanero e Diaz (2010), por exemplo, enfatizam que é comum os professores apresentarem dificuldades para o ensino da Estatística por, principalmente, não terem em sua formação inicial estudos voltados à didática desta área de conhecimento, tornando a sua abordagem, em sala de aula, restrita 
DOI: http://dx.doi.org/10.33238/ReBECEM.2019.v.3.n.2.22623

a compreensão e aplicação de algoritmos, o que pode não garantir a apropriação dos seus significados em diferentes contextos.

De modo semelhante, Carvalho (2017) argumenta que os professores também apresentam dificuldades com relação ao domínio de conceitos da Probabilidade, tanto na perspectiva da Matemática, como da sua didática; advoga, entretanto, que mediante processos formativos idôneos, os professores avançam na construção e ressignificações dos seus conhecimentos matemáticos e didáticos.

Nesse contexto, Lopes, Teodoro e Rezende (2011) apontam que é comum os conceitos da Probabilidade não serem estudados na Educação Básica em virtude de muitos professores de Matemática não se sentirem seguros para lecionar, em sala de aula, este tema, e quando o fazem, a abordagem do mesmo é pautada unicamente no tratamento de técnicas operatórias por meios de exercícios padronizados.

Diante disso, tendo em vista que o professor, responsável por apresentar o conhecimento matemático, exerce um papel primordial no processo de ensino e aprendizagem da Matemática e que a ação do mesmo determina, em grande medida, os resultados desse processo, torna-se pertinente a realização de investigações que tratem das concepções dos professores relativas ao campo estatístico e probabilístico.

Nesse sentido, com vistas a contribuir com o processo de ensino e aprendizagem da Estatística e da Probabilidade, o presente estudo tem como foco o conceito de Curva Normal, classificada como um modelo matemático de variáveis contínuas que abarca e relaciona mutuamente conceitos estatísticos e probabilísticos (GONÇALVES, 2014). Desse modo, buscou-se investigar os conhecimentos didático-matemáticos de professores de Matemática do Ensino Médio sobre a inter-relação entre a Estatística e a Probabilidade por meio da Curva Normal.

Para isso, adotou-se como referencial teórico o modelo de Conhecimentos e Competências Didático-Matemáticos - CCDM (GODINO et al., 2016), desenvolvido no seio do Enfoque Ontossemiótico do Conhecimento e da Instrução Matemática- EOS (GODINO; BATANERO, 1994; GODINO, 2012).Por meio do modelo CCDM, os autores advogam que o professor de Matemática para exercer a função docente, necessita do domínio de conhecimentos e competências que englobam tanto o conhecimento matemático, como também o conhecimento sobre a didática da Matemática, os quais são apresentados mais adiante no presente texto. 


\section{A Curva Normal de distribuição de probabilidades}

De acordo com Bayer et al., (2005), a Estatística é definida como a ciência que se ocupa da coleta, organização, análise e interpretação de dados experimentais. Além disso, segundo esses autores, a Estatística, em sua estrutura, contempla duas áreas de conhecimento: Descritiva e Inferencial.

Em linhas gerais, na ótica dos autores supracitados, a Estatística Descritiva reúne métodos para organização, resumo e descrição de dados e informações, como por exemplo, tabelas, gráficos, medidas de tendência central (médias, moda e mediana) e medidas de variabilidade ou dispersão (desvio padrão e variância). Por sua vez, a área Inferencial é responsável por dar suporte ao pesquisador, apresentando um conjunto de técnicas que buscam caracterizar e projetar o comportamento de uma população a partir dos parâmetros observáveis de uma parte dela, ou seja, uma amostra dessa população.

Nessa direção, subjacentes à Estatística Inferencial estão outros dois campos de conhecimento: a Amostragem e a Probabilidade. A primeira é caracterizada como a área responsável pelo desenvolvimento de estudos e técnicas para escolha das unidades populacionais que formarão uma determinada amostra, possibilitando que as mesmas apresentem conclusões que possam caracterizar e representar as suas respectivas populações. Por sua vez, a Probabilidade é classificada como um ramo da Matemática que trata de fenômenos aleatórios. Esta área contempla aspectos de análise combinatória, experimentos aleatórios, espaço amostral, operações com eventos e comportamentos probabilísticos de variáveis discretas e contínuas (BAYER et al., 2005).

Deste modo, a probabilidade está inter-relacionada com a Estatística servindo de alicerce para a Estatística Inferencial, possibilitando a formulação de técnicas e modelos matemáticos que possibilitam o cálculo da probabilidade de eventos, inferir e caracterizar uma população. A Distribuição Normal ou Curva Normal é considerada o principal modelo probabilístico que descreve o comportamento de variáveis contínuas, abarcando uma variedade de fenômenos do nosso cotidiano que apresentam uma Distribuição Normal ou aproximadamente normal de dados (GONÇALVES, 2014).

Nesse sentido, a Curva Normal é definida a partir dos parâmetros média $(\mu)$ e o Desvio padrão $(\sigma)$ de uma amostra. Em termos conceituais, Carzola e Santana (2006, p.18) definem a média como uma medida que "resume e representa um conjunto de dados em um único valor" e o seu cálculo "remete à divisão em partes iguais do todo entre seus componentes. Assim, seu algoritmo consiste em somar todos os valores da variável e 
DOI: http://dx.doi.org/10.33238/ReBECEM.2019.v.3.n.2.22623

dividir pelo número de dados". No que diz respeito ao Desvio Padrão, Martins (2013, p. 01) o conceitua como "uma medida de dispersão dos dados relativamente à média", ou seja, representa a distância de um dado em relação à média do conjunto ao qual esse dado pertence. Graficamente, a Curva Normal possui a seguinte representação.

\section{Figura 1: Representação da Curva Normal}

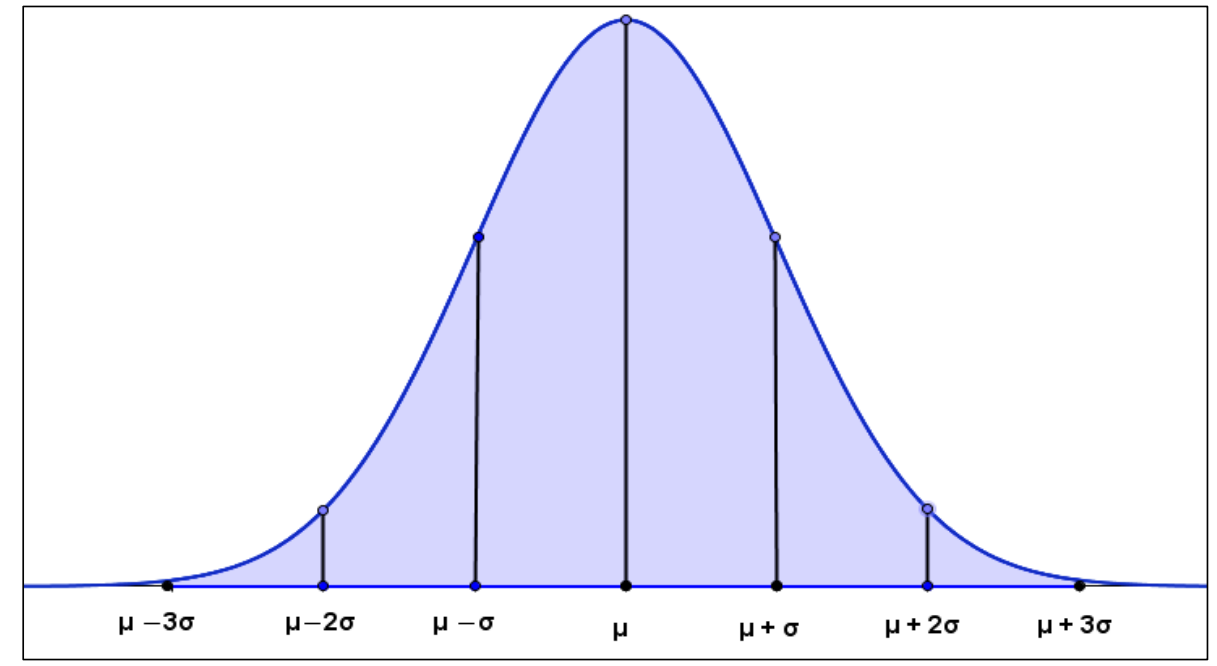

Fonte: Os Autores

A partir dessas informações, em termos matemáticos, devemos compreender que a curva reúne $100 \%$ dos dados da amostra e a área sob seu gráfico e o eixo das abscissas é sempre igual a 1. Além disso, a Curva Normal possui algumas importantes propriedades: 1) A Distribuição dos dados é simétrica em relação à média $(\mu)$, ou seja, ao centro. 2) Em toda Curva Normal, os valores de média, moda e mediana da amostra coincidem. 3) A Curva Normal possibilita determinar probabilidades associadas aos valores da área de intervalos da distribuição. 4) A probabilidade de uma variável assumir um valor entre dois pontos é determinada pela área sob a curva que os contêm.

Além disso, devemos compreender que o formato da Curva Normal depende dos referidos parâmetros média $(\mu)$ e desvio padrão $(\sigma)$ estabelecidos em cada situação. Como o valor da média $(\mu)$ estabelece o centro da Curva Normal e o desvio padrão $(\sigma)$ indica a dispersão do conjunto, isso implica que ao variá-los, o gráfico apresentará movimentos de translação e achatamento. Assim, quanto maior for o desvio padrão de uma Distribuição Normal, maior será o achatamento do gráfico, ou seja, a amplitude dos dados, definida como a diferença entre o maior e o menor valor do conjunto (AZEVEDO, 2016). Nessa situação, os dados estarão mais dispersos ou distantes da média da Distribuição. Essas informações estão exemplificadas a seguir, com dois exemplos distintos de Distribuições Normais com seus respectivos parâmetros: 
DOI: http://dx.doi.org/10.33238/ReBECEM.2019.v.3.n.2.22623

Figura 2: Representação de diferentes Curvas Normais

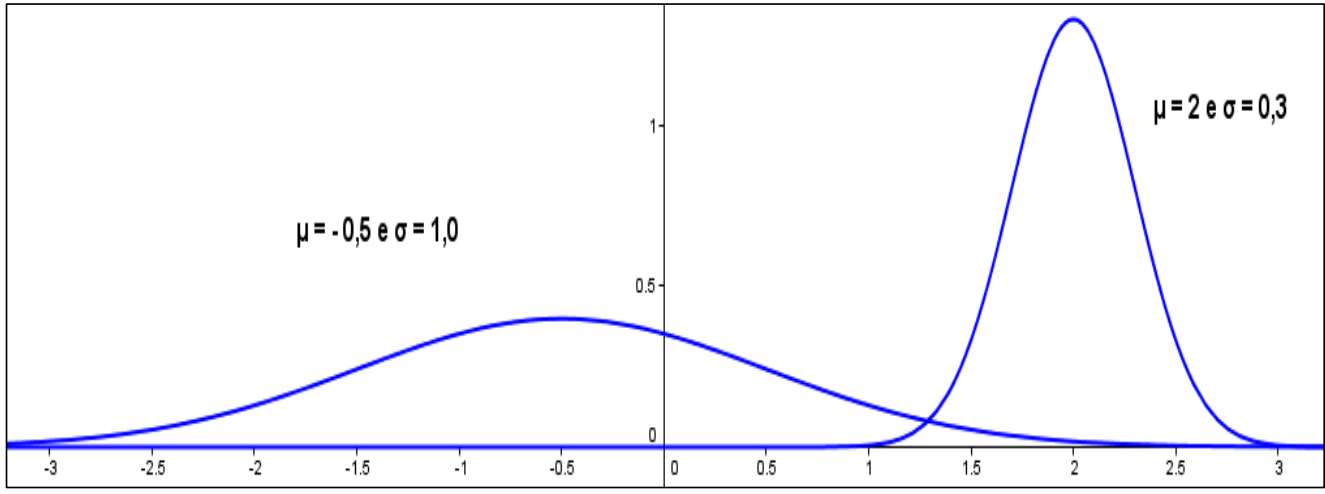

Fonte: Os Autores

\subsection{Alguns estudos antecedentes sobre o ensino e aprendizagem da Curva Normal}

No que diz respeito ao processo de ensino e aprendizagem da Curva Normal, alguns pesquisadores defendem a abordagem desse modelo matemático na Educação Básica. Tauber (2001), ao investigar o conhecimento sobre o significado da Curva Normal com graduandos de diferentes áreas, como Matemática, Ciências Econômicas e Empresariais e Ciências Sociais, constatou que tais estudantes possuem um conhecimento incipiente sobre a Estatística e a Probabilidade e mais especificamente sobre a Curva Normal. Segundo a autora, essa fragilidade está relacionada ao fato de que o ensino da Estatística na Educação Básica é pautado, por muitos docentes, à abordagem de conceitos relativos unicamente à Estatística Descritiva, ou seja, análise, interpretação de dados por meios de gráficos e tabelas, com ênfase nas medidas de tendência central.

Diante disso, a autora defende o estudo da Curva Normal na Educação Básica, como forma de propiciar aos estudantes o entendimento e aprofundamento de conceitos relativos à Estatística Inferencial e a Probabilidade, através de um ensino contextualizado que abarque situações do cotidiano dos estudantes em que a Curva Normal pode ser aplicada.

Gonçalves (2014) destaca a importância do ensino da Curva Normal, pois ela é essencial para a inferência estatística, mas que ainda é pouco abordada nas aulas de Matemática no Ensino Médio. Em seu estudo, o autor buscou apresentar uma proposta de ensino da Curva Normal, através da resolução de situações problema com auxílio do software Geogebra a ser desenvolvida em turmas do terceiro ano do Ensino Médio, buscando favorecer, aos alunos desse nível de escolarização, a construção do conhecimento relativo à inferência estatística, a Distribuição Normal e sua utilidade e aos conceitos estatísticos e probabilísticos presentes nesse modelo matemático. 


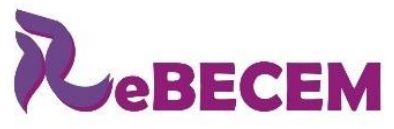

DOI: http://dx.doi.org/10.33238/ReBECEM.2019.v.3.n.2.22623
Revista Brasileira de Educação em

Ciências e Educação Matemática

Em continuidade, Lima (2009) buscou introduzir o conteúdo da Curva Normal com alunos egressos do Ensino Médioatravés de uma sequência didática baseada em resoluções de problemas e na utilização de uma planilha eletrônica como ferramenta para a construção da ideia da Curva Normal, por meio de atividades interativas envolvendo análises exploratórias de dados. Os resultados do estudo indicam que, após a realização da sequência didática, os alunos foram capazes de reconhecer a representação gráfica e compreender as propriedades e características da Curva Normal. Além disso, os alunos identificaram e se apropriaram dos conceitos estatísticos e probabilísticos relativos a esse tipo de Distribuição. O autor ainda conclui que foi possível relacionar conteúdos da Estatística com os da Probabilidade e que os alunos compreenderam a relação estabelecida entre essas áreas de conhecimento na Curva Normal.

Por fim, Macedo (2016) realizou um estudo com um grupo de professores de Matemática do Ensino Fundamental e Médio da Educação Básica, com o objetivo de investigar a ampliação da base de conhecimento desses professores sobre o ensino de noções estatísticas relativas à Curva Normal, por meio de uma formação continuada, baseada no compartilhamento de reflexões e vivências desses professores sobre o ensino desta temática. Os resultados do estudo indicam, inicialmente, que os professores não priorizavam o ensino da Curva Normal em suas aulas e apresentaram concepções inconsistentes sobre os conceitos estatísticos presentes nesse tipo de Distribuição.

No entanto, após o processo formativo, o autor conclui que os professores ressignificaram os conceitos estatísticos e compreenderam a importância do ensino da Curva Normal, e assim, ampliaram a base de conhecimentos relativa ao ensino da Estatística e da Probabilidade. Macedo (2016) ainda destaca a necessidade de processos formativos para os professores de Matemática da Educação Básica, que contemplem diferentes abordagens, estratégias, contextos e materiais direcionados ao ensino e aprendizagem da Curva Normal.

\section{Modelo de Conhecimentos e Competências Didático-Matemáticos - CCDM}

Com vistas a analisar o conhecimento de professores de Matemática do Ensino Médio sobre a inter-relação entre a Estatística e a Probabilidade por meio da Curva Normal, adotamos como aporte teórico as ideias de Godino (2009); Pino-Fan e Godino (2015) sobre o modelo Conhecimentos e Competências Didático-Matemáticos - CCDM, 
DOI: http://dx.doi.org/10.33238/ReBECEM.2019.v.3.n.2.22623

desenvolvido a partir das noções teóricas do Enfoque Ontossemiótico do Conhecimento e da Instrução Matemática-EOS (GODINO; BATANERO, 1994).

No referido modelo, o conhecimento didático-matemático é classificado como o saber docente relativo à Matemática e ao seu ensino e que estão relacionados no processo de ensino e aprendizagem da Matemática. Já a competência, diz respeito uma "ação efetiva realizada em um contex to específico com um propósito específico" (FONT, 2011, p. 18). No entanto, diante do nosso objetivo, focaremos nesse estudo apenas nos conhecimentos didático-matemáticos que o professor de Matemática deve compreender, saber aplicar e avaliar, para que possa exercer sua prática docente de forma eficiente.

Figura 3:Conhecimento Didático-Matemático

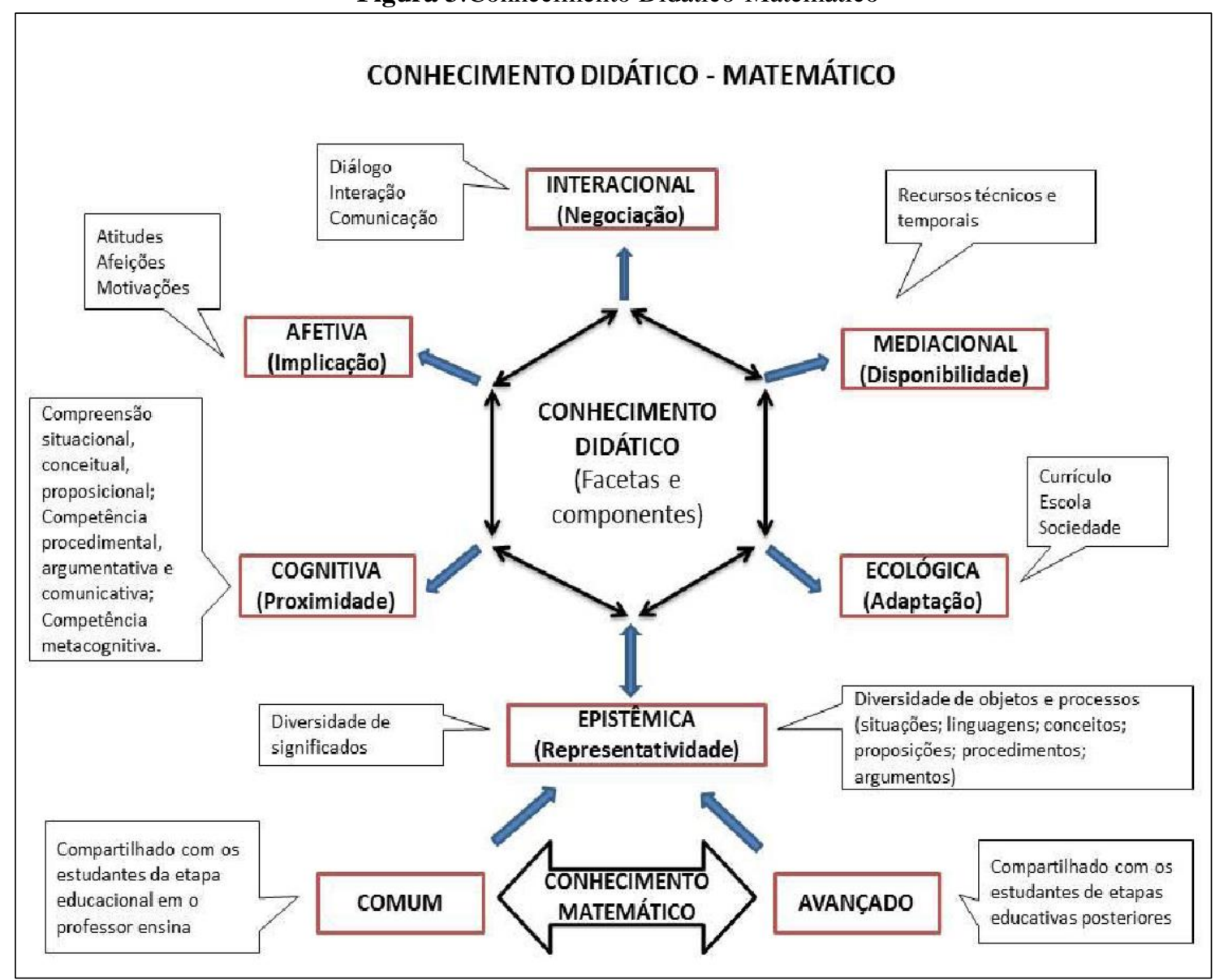

Fonte: Godino (2016); Carvalho (2017)

Discorrendo sobre as características das categorias de conhecimento matemático, Pino-Fan e Godino (2015) enfatizam que o conhecimento matemático comum do conteúdo corresponde ao conhecimento do professor sobre um objeto específico matemático, capaz de resolver problemas ou atividades matemáticas relacionadas a esse objeto e que deve ser abordado com os alunos em cada etapa da escolarização em que o professor se propõe a desenvolver o processo de ensino e aprendizagem sobre esse 
DOI: http://dx.doi.org/10.33238/ReBECEM.2019.v.3.n.2.22623

conteúdo. No ensino da Curva Normal, por exemplo, o conhecimento comum do conteúdo diz respeito ao domínio de conceitos, definições, procedimentos operatórios e algoritmos a serem abordados no Ensino Médio da Educação Básica e suficientemente para resolver problemas e interpretar dados e informações estatísticas e probabilísticas apresentadas nesse tipo de Distribuição.

O conhecimento matemático avançado do conteúdo, por sua vez, corresponde ao conhecimento sobre os conteúdos matemáticos que devem ser ensinados nas etapas educativas posteriores. Deste modo, o professor deve ter domínio do conhecimento matemático escolar no nível educacional onde ele ensina, mas também deve ser capaz de articular este conhecimento com aqueles correspondentes que serão abordados em níveis educacionais subsequentes.

Em relação à faceta Epistêmica, a mesma contempla o conhecimento matemático que vai além daqueles abarcados pelas categorias "comum" e "avançado" do conteúdo. Assim, diz respeito ao conhecimento sobre a pluralidade de significados que os objetos matemáticos podem assumir, levando em consideração as diferentes situações e contextos que os mesmos estão inseridos, as diversas representações que podem ser mobilizadas e as relações entre os conceitos matemáticos, objetos e processos abarcados em cada situação. Deste modo, a partir desse conhecimento, o professor deve ser capaz, por exemplo, de resolver uma tarefa matemática por diferentes procedimentos, mobilizar diferentes representações e reconhecer os diversos significados dos objetos matemáticos emergidos durante a resolução. Particularmente, em nosso caso, esse conhecimento abarca os diferentes significados e representações em que a Curva Normal pode assumir em diversas situações e aplicações, bem como as relações entre os conceitos estatísticos e probabilísticos presentes nesse modelo.

A faceta cognitiva, por sua vez, está relacionada com o conhecimento sobre aspectos e a forma como os estudantes aprendem, raciocinam, entendem a Matemática e como progridem na sua aprendizagem. Já a faceta afetiva (emocional), corresponde ao grau de conhecimento sobre aspectos emocionais e comportamentais, como também as crenças e atitudes dos estudantes sobre os objetos matemáticos no processo de ensino e aprendizagem da Matemática.

Em continuidade, a faceta mediacional corresponde ao conhecimento sobre a disponibilização e utilização de recursos (tecnológicos, materiais) que podem ser utilizados para abordagem de conteúdos, a fim de potencializar o processo de ensino aprendizagem. Em relação à faceta interacional, ela corresponde ao conhecimento sobre 
DOI: http://dx.doi.org/10.33238/ReBECEM.2019.v.3.n.2.22623

o ensino da Matemática, organização de atividades para o ensino e os diversos tipos de interações que podem ocorrer na sala de aula, que são consideradas essenciais para o processo de ensino e aprendizagem da Matemática, isto é, alunos com o professor, alunos entre si e alunos com os recursos didáticos. A faceta ecológica, por sua vez, corresponde ao conhecimento sobre a relação dos conteúdos matemáticos com outras disciplinas, o currículo proposto para o ensino de Matemática e os fatores do cotidiano, como sociais, incluindo a comunidade escolar, políticos e econômicos que estão subjacentes ao processo de ensino e aprendizagem da Matemática.

Por fim, Pino-Fan e Godino (2015) e Carvalho (2017) destacam que todos esses componentes e facetas didático-matemáticos estão relacionadas entre si no processo de ensino e aprendizagem da Matemática e assim, faz-se necessário que o professor tenha domínio sobre todos eles. Desta forma, ao exercer a prática docente o professor deve ser capaz de mobilizar, aplicar e reconhecer tais dimensões.

\section{Procedimentos metodológicos}

Em termos metodológicos, essa investigação utiliza uma abordagem qualitativa. Sobre esse tipo de abordagem, Oliveira (2011, p. 28) classifica "como sendo um processo de reflexão e análise da realidade através da utilização de métodos e técnicas para compreensão detalhada do objeto de estudo em seu contexto histórico e/ou segundo a sua estruturação". No presente estudo, ao investigarmos os conhecimentos didáticomatemáticos de professores de Matemática do Ensino Médio sobre a inter-relação entre a Estatística e a Probabilidade por meio da Curva Normal, buscamos compreender o significado que os professores atribuem a este modelo matemático, aos conceitos estatísticos e probabilísticos que o mesmo abarca e as noções didáticas relativas ao seu processo de ensino e aprendizagem.

Além disso, essa investigação se constitui como um estudo parcial de uma pesquisa dissertativa em andamento, a qual envolve um grupo de 15 professores de Matemática do Ensino Médio da rede pública do estado de Pernambuco. A escolha por professores desse nível de escolarização está fundamentada na Base Nacional Comum Curricular para o Ensino Médio (BRASIL, 2018) e nos Parâmetros para a Educação Básica do Estado de Pernambuco, (PERNAMBUCO, 2013), os quais, em linhas gerais, orientam a abordagem da Curva Normal nesta etapa da Educação Básica. 


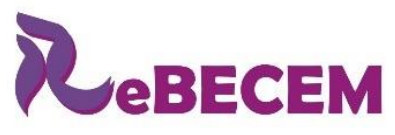

DOI: http://dx.doi.org/10.33238/ReBECEM.2019.v.3.n.2.22623
Revista Brasileira de Educação em

Ciências e Educação Matemática

Os dados aqui apresentados e discutidos foram coletados a partir das informações obtidas pelas respostas de três professores de Matemática, identificados no presente texto por $\mathrm{P}_{1}, \mathrm{P}_{2}$ e $\mathrm{P}_{3}$, que participaram do estudo piloto dessa pesquisa. A coleta desses dados foi realizada a partir das respostas produzidas por meio do Questionário Diagnóstico composto por 6 questões relativas ao conhecimento didático-matemático sobre a relação recíproca entre a Estatística e a Probabilidade envolvida pelo modelo da Curva Normal. A escolha por esse tipo de instrumento foi por entender que "o questionário é considerado um importante instrumento de pesquisa por fornecer subsídios reais do universo ou da amostra pesquisada" Oliveira (2011, p. 44), permitindo, no presente estudo, a investigação sobre o conhecimento didático-matemático dos professores relativo ao tema supracitado.

Como critério de análise de dados, classificamos as respostas dos professores a partir de três categorias, a saber: Resposta Adequada (RA); Resposta Parcialmente Adequada (RPA) ou Resposta Inadequada (RI). A escolha por esse método de classificação seu deu por acreditar que o mesmo possibilita, de modo satisfatório, identificar, compreender e caracterizar os dados coletados a partir do objetivo de cada questão presente no questionário diagnóstico. Na seção seguinte, apresentaremos as referidas questões que compõem o questionário, as categorizações emergentes das respostas dos professores e a discussão dos resultados.

\section{Análise de resultados}

Como discorrido na seção anterior, apresentaremos aqui as questões que compõem o questionário diagnóstico aplicado aos professores, concomitantemente, com a discussão dos resultados das análises, diante das categorizações emergentes das respostas dos participantes, apresentadas, a seguir, com o auxílio dos excertos ${ }^{3}$.

Questão 1- Você acredita que existe alguma relação entre a Estatística e a Probabilidade? Caso positivo, como compreendes essa relação? Justifique sua resposta. Essa questão teve como objetivo identificar o conhecimento didático-matemático epistêmico sobre a relação entre a Estatística e a Probabilidade.

Categoria de análise observada: Resposta Parcialmente Adequada (RPA) Quando o participante diz acreditar que existe alguma relação teórica entre a Estatística e

\footnotetext{
${ }^{3}$ Para melhor visualização/compreensão, apresenta-se, após os excertos, a reescrita das respostas dos
} participantes dessa pesquisa. 
DOI: http://dx.doi.org/10.33238/ReBECEM.2019.v.3.n.2.22623

a Probabilidade, mas não consegue apresentar em sua justificativa, um conhecimento epistêmico sobre a relação teórica entre a Estatística e a Probabilidade.

As respostas dos três professores participantes a esta questão tiveram a mesma categorização, por eles afirmarem acreditar que existe uma relação entre a Estatística e a Probabilidade, mas, em suas justificativas, se resumiram a apresentar aplicações ou utilidades da Estatística e da Probabilidade, não explicitando de forma coerente noções da relação teórica existente entre essas duas áreas de conhecimento. Dessa forma, evidencia-se uma lacuna sobre o conhecimento matemático epistêmico sobre tal relação, como podemos exemplificar na Figura 4, a seguir, que contempla a resposta do professor $\mathrm{P}_{2}$.

Figura 4:Resposta RPA do professor $\mathrm{P}_{2}$ à $1^{\circ}$ questão ${ }^{4}$

$\left.1^{\circ}\right)$ Você acredita que existe alguma relação entre a Estatística e a Probabilidade? Caso positivo, como compreendes essa relação, justifique sua resposta.

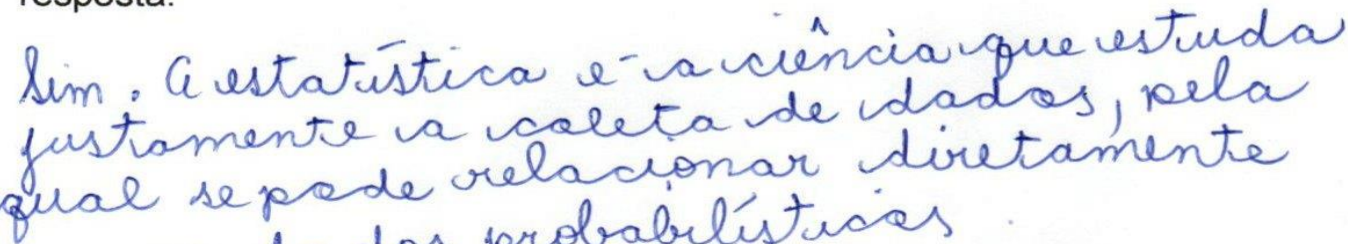

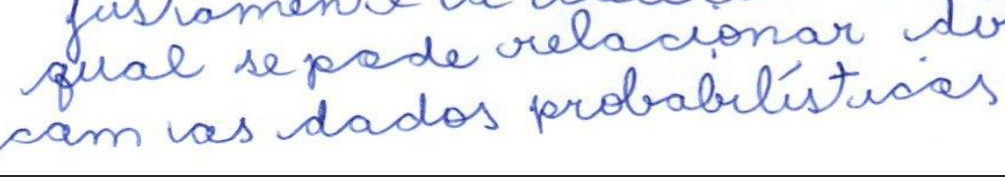

Fonte: Dados da pesquisa

Questão 2- De que forma você abordaria uma proposta de aula articulando a Estatística com a Probabilidade em uma aula de Matemática com estudantes do Ensino Médio? Se desejar, pode incluir exemplos de atividades. Essa questão, por sua vez, buscou analisar o conhecimento didático envolvendo todas as seis facetas.

Categoria de análise observada: Resposta Parcialmente Adequada (RPA) Quando o participante consegue apresentar uma proposta de aula que contemple Estatística e a Probabilidade, contemplando noções de conhecimento didático envolvendo pelo menos uma das seis facetas didáticas.

Nessa questão, os professores apresentaram, em suas respostas, propostas de uma aula de Matemática para o Ensino Médio que articulasse a Estatística e a Probabilidade. Ao analisarmos tais propostas, observamos que os três professores a responderam de forma parcialmente adequada. Nesse sentido, foi perceptível a presença do conhecimento didático envolvendo algumas facetas, como a interacional, mediacional e ecológica, como

\footnotetext{
${ }^{4}$ Sim. A Estatística é a ciência que estuda justamente a coleta de dados, pela qual se pode relacionar diretamente com os dados probabilísticos.
} 
DOI: http://dx.doi.org/10.33238/ReBECEM.2019.v.3.n.2.22623

podemos observar na figura, a seguir, que contempla a resposta do professor $\mathrm{P}_{1}$ à referida questão.

Figura 5: Resposta RPA do professor $\mathrm{P}_{1}$ à $2^{\circ}$ questão ${ }^{5}$

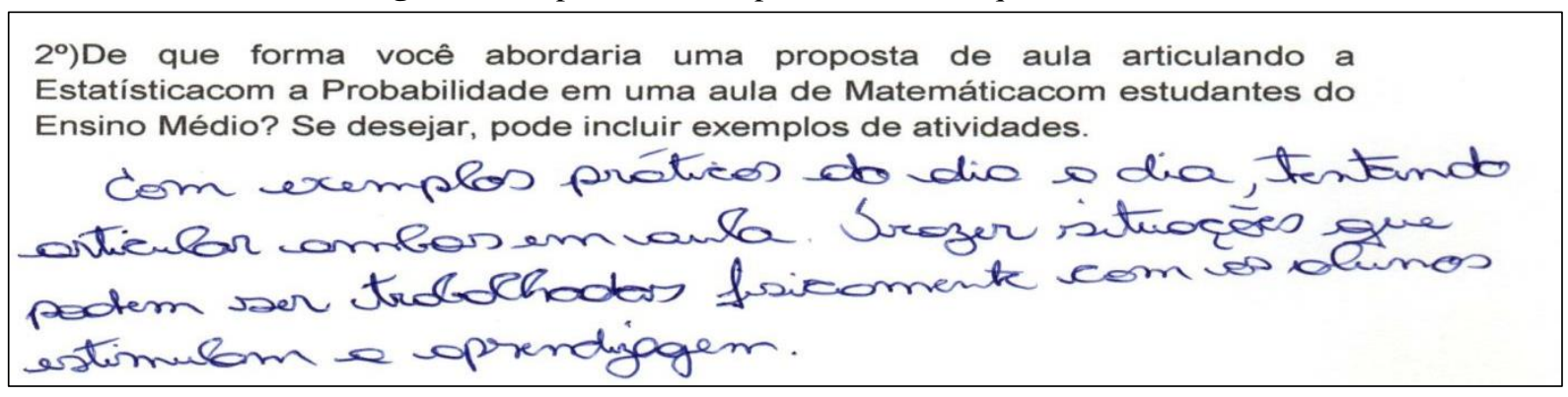

Fonte: Dados da pesquisa

Além disso, evidenciou-se que a lacuna relativa ao conhecimento matemático epistêmico, observada na questão anterior, acarreta, em certa medida, em um conhecimento didático da mesma forma sobre tal relação, tendo em vista que, como enfatizam Pino-Fan e Godino (2015), os conhecimentos matemáticos e didáticos se relacionam no processo de ensino e aprendizagem e se constituem de um domínio necessário para o professor realizar sua prática docente.

Questão 3- Dos termos abaixo, utilizados em Estatística, quais você conhece e se julga capaz de conceituar? Marque com X e em seguida conceitue.

( ) Média

( ) Amplitude

( ) Desvio padrão

( ) Amostragem

Essa questão se apresenta com o objetivo de analisar o conhecimento matemático comum de conteúdo dos professores participantes da pesquisa sobre alguns termos conceituais presentes na Estatística.

Categoria de análise observada: Resposta Parcialmente Adequada (RPA)- O participante conhece alguns dos termos mencionados na questão, mas só consegue conceituar algum (ns) dos termos mencionados, apresentando noções de conhecimento matemático comum.

Em continuidade, com relação à $3^{\circ}$ questão, as noções conceituais apresentadas pelos professores aos termos estatísticos: Amostragem, Média, Desvio Padrão e

\footnotetext{
${ }^{5}$ Com exemplos práticos do dia a dia, tentando articular ambas em aula, trazer situações que podem ser trabalhadas fisicamente com os alunos e estimular a aprendizagem.
} 
DOI: http://dx.doi.org/10.33238/ReBECEM.2019.v.3.n.2.22623

Amplitude, contemplados nessa questão, foram analisadas a partir de suas definições conceituais, desenvolvidas respectivamente por Bayer et al., (2015), Carzola e Santana(2006), Martins (2013) e Azevedo (2016), que estão apresentadas no presente estudo. Nessa direção, ao analisar as respostas apresentadas pelos professores, constatamos que todas se enquadram na categoria RPA.

Os participantes demonstram conhecer alguns dos termos mencionados na questão, mas só conseguiram conceituar de modo adequado, a partir da apresentação de noções de conhecimento matemático comum, o termo "Média", como podemos observar, na figura a seguir, a resposta apresentada pelo professor $\mathrm{P}_{1}$.

Figura 6: Resposta RPA do professor $\mathrm{P}_{1}$ à $3^{\circ}$ questão ${ }^{6}$

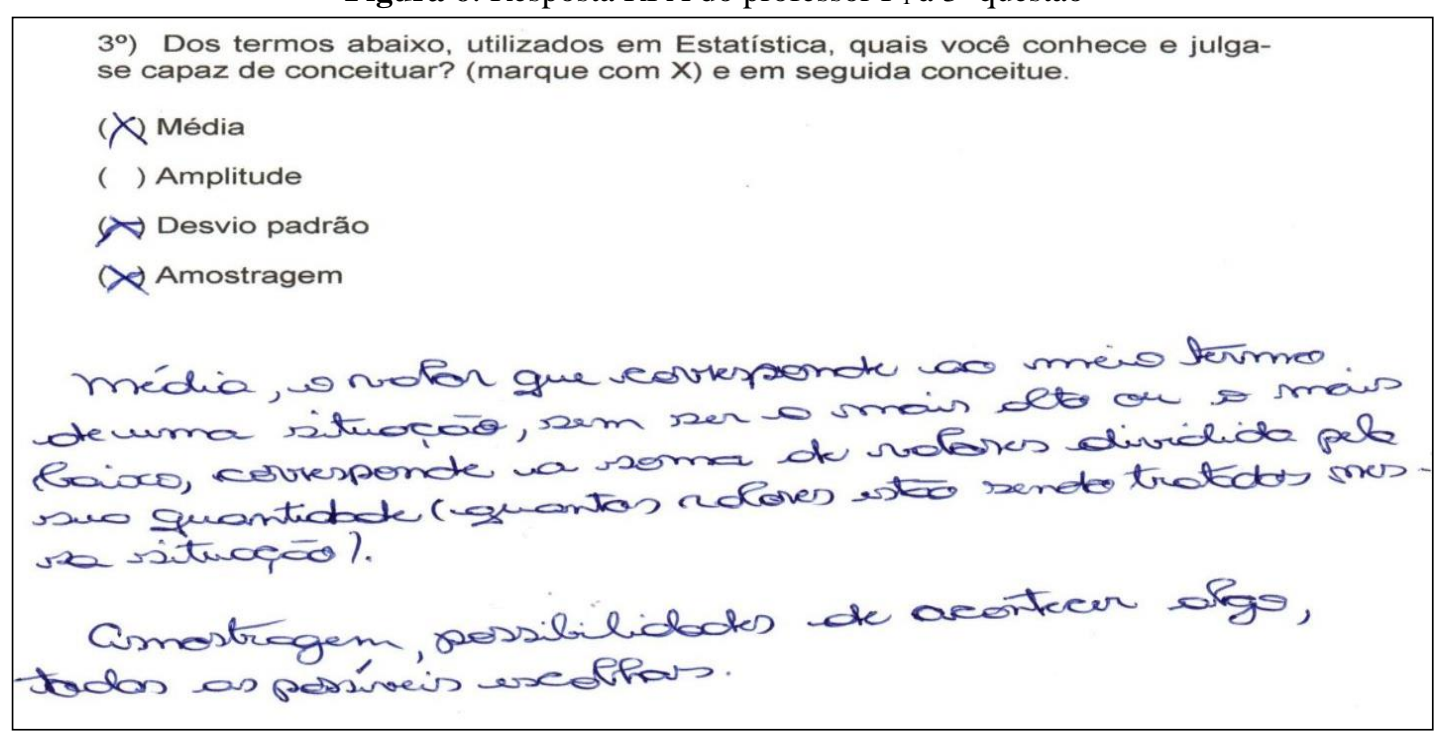

Fonte: Dados da pesquisa

Diante disso, por meio das respostas dos professores, podemos inferir que o fato dos mesmos apresentarem, de modo adequado, apenas o conceito de Média, pode estar relacionado ao domínio conceitual desses professores sobre as medidas de tendência central (Média, Moda e Mediana) e serem esses os termos que eles mais conhecem e têm privilegiado ao lecionar, quando abordam a Estatística na disciplina de Matemática (SANTANA, 2016), o que acaba não garantindo a abordagem e domínio de outros conceitos estatísticos, comumente presentes em diversas situações e fenômenos do nosso cotidiano, como Amostragem, Desvio padrão e Amplitude.

\footnotetext{
${ }^{6}$ Média, o valor que corresponde ao meio termo de uma situação, sem ser o mais alto ou o mais baixo. Corresponde a soma de valores dividida pela sua quantidade (quantos valores estão sendo tratados nessa situação). Amostragem, possibilidades de acontecer algo, todas as possíveis escolhas.
} 
DOI: http://dx.doi.org/10.33238/ReBECEM.2019.v.3.n.2.22623

Questão 4-(a) O que você conhece sobre a distribuição normal ou curva normal?

Podes nos falar sobre este conceito? (Não precisa ser uma definição formal).

b) Acreditas que a curva normal deve ser trabalhada com os estudantes na etapa de escolarização do Ensino Médio? Justifique sua resposta.

A quarta questão contempla duas alternativas. A primeira alternativa buscou analisar o conhecimento matemático comum e epistêmico dos professores sobre a Curva Normal. Já a segunda tem por objetivo analisar o conhecimento didático, envolvendo a faceta ecológica dos professores sobre a abordagem de Curva Normal no Ensino Médio.

Categoria de análise observada: Alternativa (a): Resposta Inadequada (RI)- O participante não apresenta noções de conhecimento matemático comum e epistêmico sobre o conceito da Curva Normal. Alternativa (b): Resposta Parcialmente Adequada (RPA)- O participante acredita que a Curva Normal deve ser ensinada no Ensino Médio, mas não justifica sua resposta apresentando noções de conhecimento didático, envolvendo a faceta ecológica.

Em relação à $4^{\circ}$ questão-alternativa (a), as respostas apresentadas pelos três professores indicam que os mesmos não conhecem ou não têm o domínio do conceito da Curva Normal, o que faz as respostas apresentadas se enquadrar na categoria RI. Esse dado sinaliza que os participantes apresentam uma lacuna sobre o conhecimento comum e epistêmico da Curva Normal e que, possivelmente, não tiverem formação voltada para este conceito. Como podemos observar, a seguir, na resposta fornecida pelo professor $\mathrm{P}_{3}$.

Figura 7: Resposta RPA do professor $\mathrm{P}_{3}$ à $4^{\circ}(\mathrm{a})^{7}$

$\left.4^{\circ}\right)$

a) O que você conhece sobre a distribuição normal ou curva normal? Podes nos falar sobre este conceito? (não precisa ser uma definição formal).

náo sei infoumar.

\section{Fonte: Dados da pesquisa}

Com relação à alternativa (b) da $4^{\circ}$ questão, os três professores afirmam que a Curva Normal deve ser trabalha no Ensino Médio, no entanto, nas suas respectivas justificativas, não fica evidenciado noções do conhecimento didático envolvendo a faceta ecológica sobre o conceito da Curva Normal, pautado nas normas e expectativas de aprendizagem presentes nos currículos e documentos oficiais da educação, como o

${ }^{7}$ Não sei informar. 
DOI: http://dx.doi.org/10.33238/ReBECEM.2019.v.3.n.2.22623

Parâmetros Curriculares do Estado de Pernambuco (PERNAMBUCO, 2013), que contempla este conceito para a etapa do Ensino Médio. Isto nos leva a configurar as respectivas respostas na categoria resposta parcialmente adequada (RPA). A figura a seguir exemplifica a resposta do professor $\mathrm{P}_{2}$ para essa questão.

Figura 8: Resposta RPA do professor $\mathrm{P}_{1}$ à $4^{\circ}(\mathrm{b})^{8}$

b) Acreditas que a curva normal deve ser trabalhada com os estudantes na etapa de escolarização do Ensino Médio? Justifique sua resposta.

Sim. Ceda connits desx de Estatistice possibilife

cos alunos Compruenderem os dados sitwaciés

que o lerla mo cotidions.

Fonte: Dados da pesquisa

Questão 5 - Foi medida a temperatura (em graus Celsius) em duas cidades no horário das 6:00 da manhã e os resultados estão apresentados nas Figuras abaixo.

Figura 9: Medidas de temperatura da cidade A no período de 46 dias

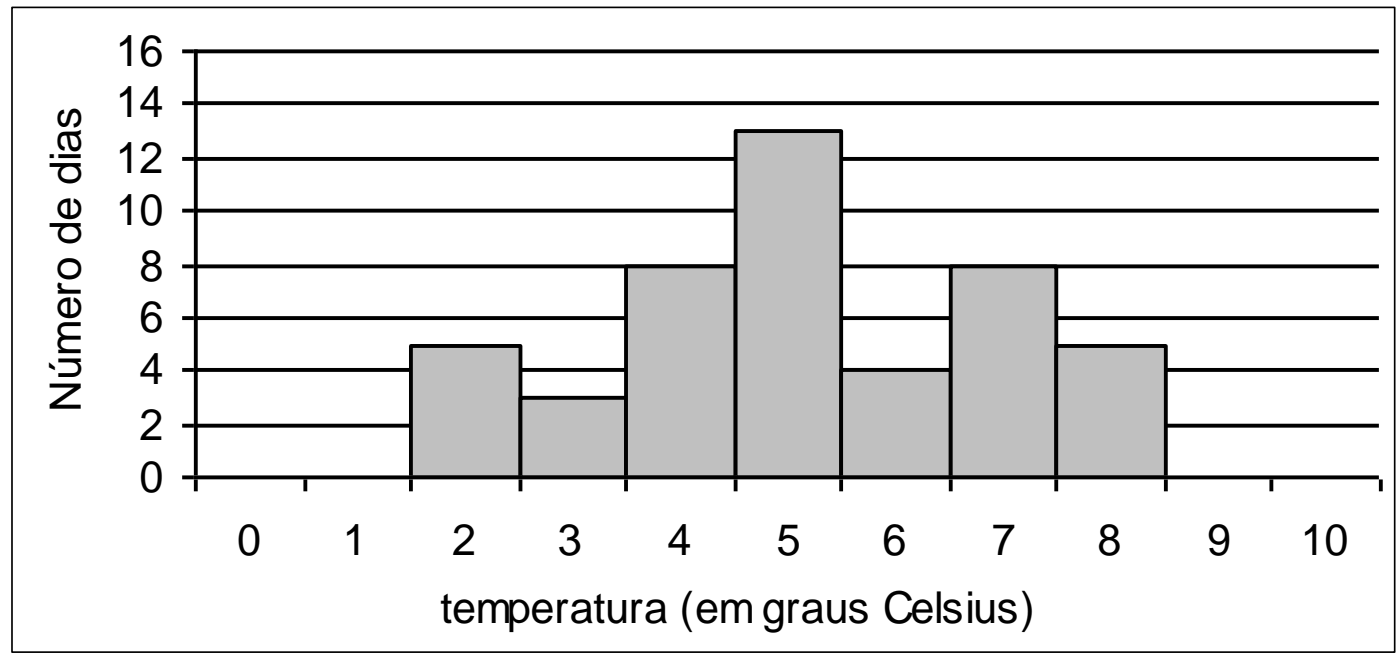

Fonte: Os autores

${ }^{8}$ Sim. Cada conceito desse de Estatística possibilita aos alunos compreenderem os dados e situações que o cerca no cotidiano. 
DOI: http://dx.doi.org/10.33238/ReBECEM.2019.v.3.n.2.22623

Figura 10: Medidas de temperatura da cidade B no período de 74 dias

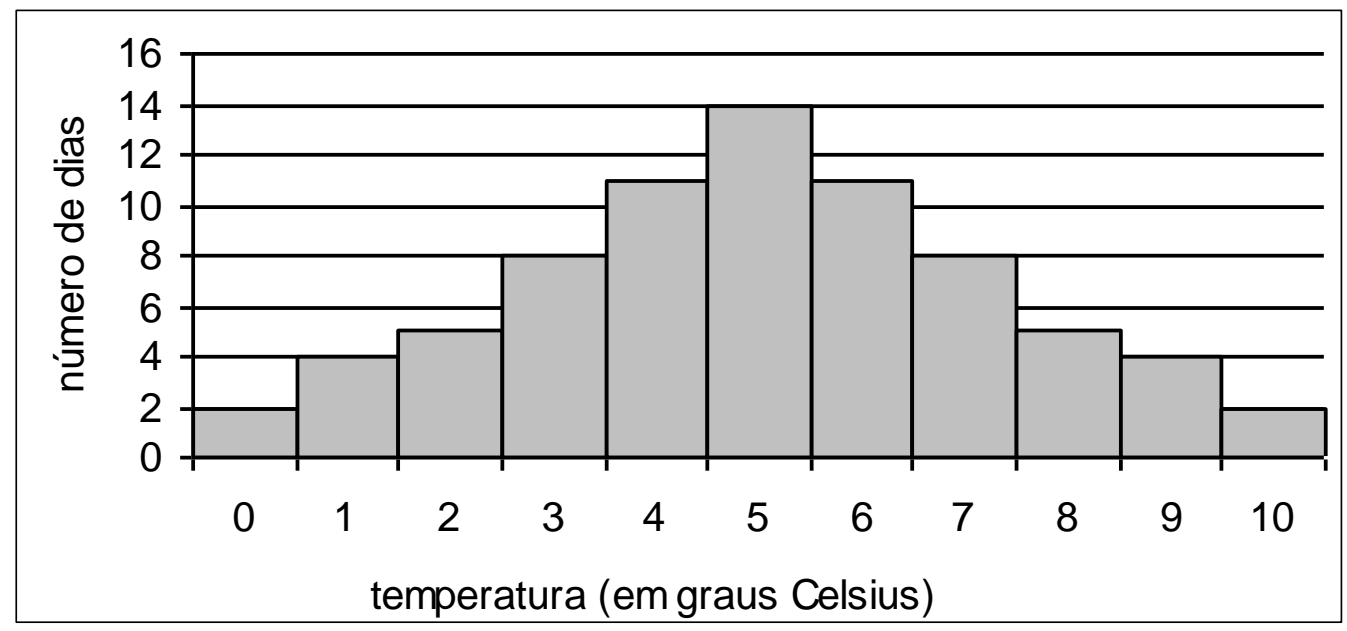

Fonte: Os autores

Sabendo-se que a média de temperatura das duas cidades é 5, é CORRETO afirmar que:

(a) O desvio padrão da temperatura é maior na cidade $\mathrm{A}$, pois o gráfico tem um formato irregular.

(b) O desvio padrão da temperatura é maior na cidade $\mathrm{B}$, pois a menor temperatura foi zero e a maior temperatura foi 10 .

(c) $\mathrm{O}$ desvio padrão da temperatura é menor em $\mathrm{B}$, porque na maioria dos dias a temperatura ficou perto de 5 .

(d) $\mathrm{O}$ desvio padrão da temperatura é menor em $\mathrm{A}$, porque na maioria dos dias não houve temperaturas abaixo de 2 e nem acima de 9 .

(e) O desvio padrão é maior em A, pois na maioria dos dias a temperatura ficou próxima de cinco e não houve dias com temperaturas abaixo de 2 e nem acima de 9.

Nessa questão, por meio de uma situação-problema envolvendo representações gráficas, o objetivo é a análise do conhecimento matemático comum de conteúdo dos professores sobre o conceito de desvio-padrão e média.

Categorias de Análise Observadas: Resposta Adequada (RA) - Quando o participante assinala a alternativa contendo a resposta correta da questão ou Resposta Inadequada (RI)- O participante assinala uma alternativa que não contém a resposta correta da questão.

Essa questão, por sua vez, abordou uma situação-problema envolvendo o conceito de desvio Padrão e média, através de duas representações gráficas, sendo uma delas a representação da Curva Normal. Nesse sentido, por se tratar de uma questão objetiva e de múltipla escolha, os professores deveriam, com base informações e dados contidos nos 


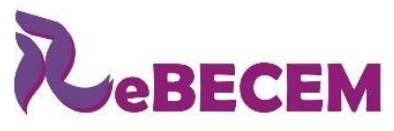

DOI: http://dx.doi.org/10.33238/ReBECEM.2019.v.3.n.2.22623
Revista Brasileira de Educação em

Ciências e Educação Matemática

gráficos, demarcar uma das alternativas como resposta, sendo a alternativa (b) a resposta correta da referida questão. Ao analisar as respostas, constatamos que apenas o professor $\mathrm{P}_{1}$ a respondeu corretamente, esse dado sinaliza que o mesmo compreendeu corretamente o significado do Desvio Padrão e de Média envolvido na questão e concluiu, a partir das informações e dados contidos nos gráficos apresentados, que o maior Desvio Padrão da temperatura é o da cidade B, ou seja, expressa um maior grau de dispersão dos dados da temperatura em relação à média, quando comparado com os dados da cidade A. Isto configura sua resposta na categoria Resposta Adequada (RA).

Já os professores $\mathrm{P}_{2}$ e $\mathrm{P}_{3}$ assinalaram como resposta a alternativa (d). Sobre a afirmação posta nesta alternativa, de fato o desvio padrão é menor em A, mas a informação complementar "porque na maioria dos dias não houve temperatura abaixo de 2 nem acima de 9" a torna incorreta, tendo em vista que em nenhum dos dias na cidade A houve temperatura menor que 2 ou acima de 9 e a expressão "nenhum dos dias", nesse contexto, não tem o mesmo significado de "na maioria dos dias". Isto faz as respostas dos referidos professores se enquadrarem na categoria Resposta Inadequada (RI). Além disso, podemos concluir que por se tratar de uma situação problema, os mesmos não interpretaram ou compreenderam as informações expostas nos gráficos da referida questão.

$6^{\circ}$ Questão- Vamos introduzir bolas em tabuleiro retangular como este. Em seu interior há obstáculos circulares de cor cinza, como mostra a figura. O tabuleiro é colocado verticalmente de forma que, quando se introduz uma bola, ela desliza entre os obstáculos circulares até atingir a parte inferior do tabuleiro, formada por recipientes retangulares. Deste modo, durante sua trajetória de descida, a bola pode se chocar com alguns dos obstáculos circulares e se dirigir para a direita ou para esquerda para, em seguida, tropeçar de novo e mudar de direção até chegar a um dos recipientes retangulares na parte inferior do tabuleiro e parar.

a) Você pode fazer uma distribuição de como as bolas ficaram organizadas nas recipientes retangulares finais, após todas as bolas terem caído? 
DOI: http://dx.doi.org/10.33238/ReBECEM.2019.v.3.n.2.22623

Figura 11: Tabuleiro

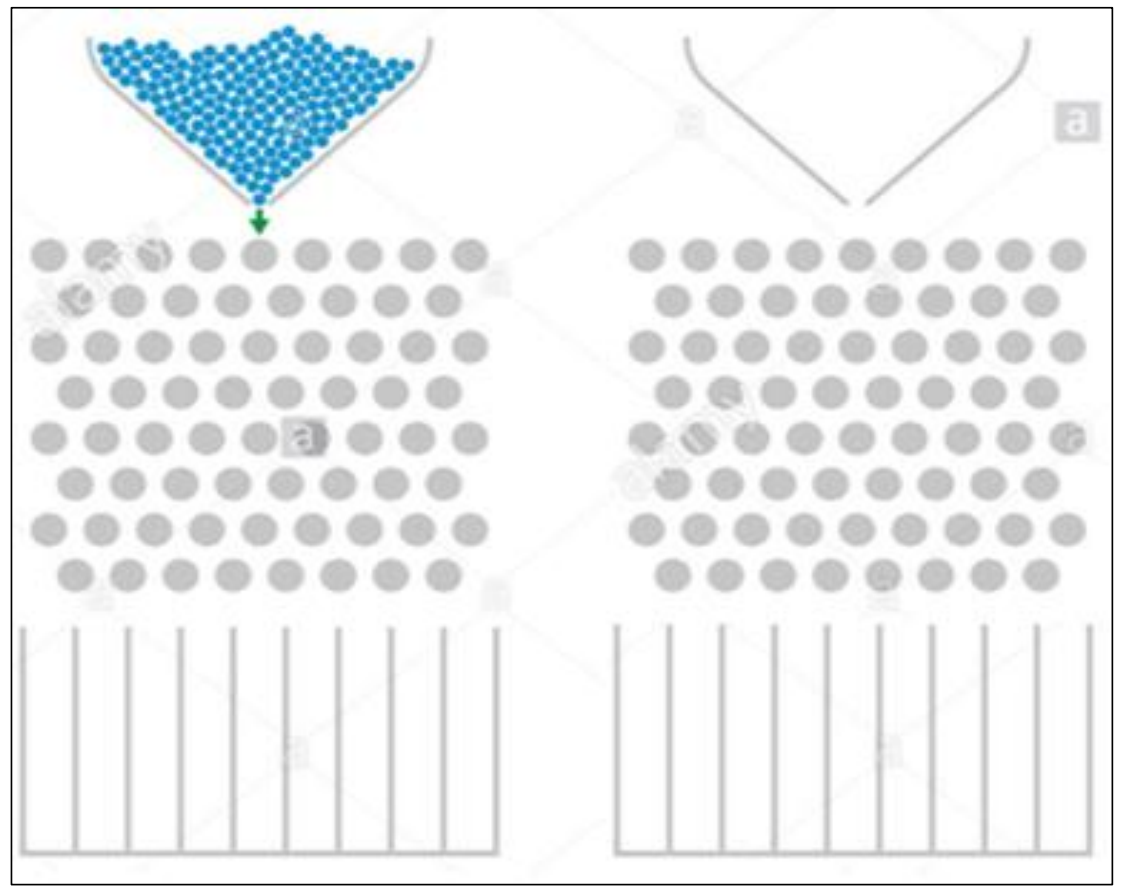

Fonte: Os autores

b) Professor(a), imagine que você está ensinando Matemática em uma turma do Ensino Médio e colocastes este problema anterior para os alunos resolverem. A seguir estão as respostas de três grupos diferentes. A partir das respostas apresentadas, como você prosseguiria com a discussão em classe? 
DOI: http://dx.doi.org/10.33238/ReBECEM.2019.v.3.n.2.22623

Figura 12: Resposta de 3 grupos de alunos

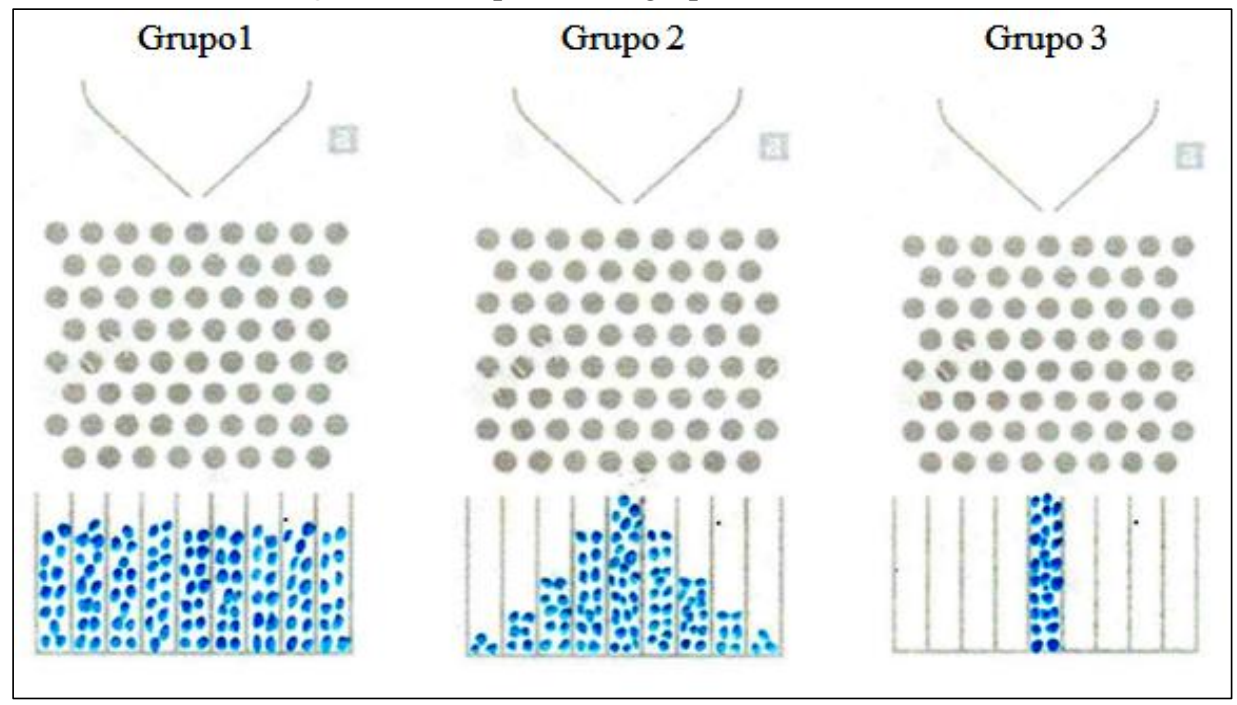

Fonte: Os autores

Por fim, a questão 6 contempla duas alternativas: A primeira buscou analisar o conhecimento matemático comum dos professores sobre a Curva Normal, através de uma situação problema. A segunda alternativa, por sua vez, tem por objetivo analisar o conhecimento didático, envolvendo a faceta cognitiva, afetiva, interacional e a mediacional dos professores participantes a partir de respostas de grupos de alunos a mesma situação problema proposta ao professores.

Categorias de Análise Observadas: Alternativa (a): Resposta Inadequada (RI)-O participante apresenta a organização das bolas não obedecendo a uma Distribuição Normal. Alternativa (b): Resposta Parcialmente Adequada (RPA) - O participante consegue mencionar a forma como prosseguiria a discussão com a classe, apresentando noções de conhecimento didático, envolvendo a faceta cognitiva, afetiva e interacional ou mediacional, e Resposta Adequada (RA) - O participante consegue mencionar a forma como prosseguiria a discussão com a classe, apresentando noções de conhecimento didático, envolvendo a faceta cognitiva, afetiva, interacional e mediacional.

Em continuidade, a $6^{\circ}$ questão - Alternativa A - abordou uma situação envolvendo o tabuleiro de Galton, dispositivo desenvolvido pelo matemático inglês Francis Galton. Nele, bolas são jogadas a partir do topo e ao descerem batem em pinos circulares, se distribuindo para a esquerda ou para a direita. Ao caírem nas bandejas inferiores, as bolas acumuladas apresentam uma Distribuição Normal. Logo, nessa questão, os professores foram convidados a desenhar como as bolas ficariam distribuídas após descerem pelo tabuleiro e caírem nas bandejas inferiores. Nesta direção, ao analisarmos a respostas fornecidas pelos professores constatamos que todos eles responderem de modo 
DOI: http://dx.doi.org/10.33238/ReBECEM.2019.v.3.n.2.22623

inadequado. Para exemplificar, apresentamos a seguir a resposta fornecida pelo professor $\mathrm{P}_{1}$ :

Figura 13: Resposta RI do professor $\mathrm{P}_{1}$ à $6^{\circ}$ (a)

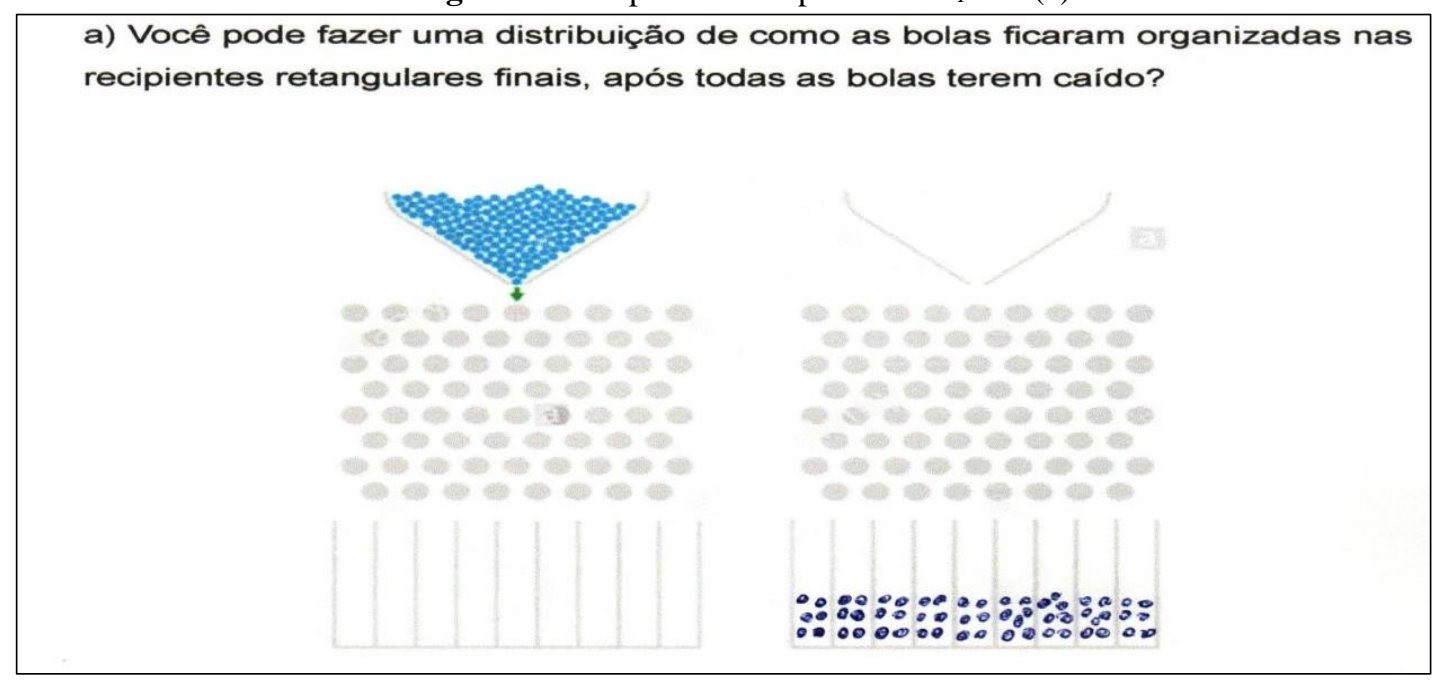

Fonte: Dados da pesquisa

Diante disso, destacamos que essas observações corroboram com as conclusões levantas na questão $4^{\circ}$ desse questionário. Os professores participantes deste estudo, por não possuírem um conhecimento comum sobre o conceito de Distribuição Normal, não compreendem também algumas situações ou fenômenos que abarcam tal distribuição.

Por fim, na $6^{\circ}$ questão - Alternativa $\mathrm{B}$, apresentamos exemplos de respostas de 3 grupos de estudantes à questão abordada no item anterior e indagamos aos professores a forma como eles prosseguiriam a discussão com classe de alunos a partir das respostas apresentas pelos grupos. Destacamos, a seguir, os comentários do professor $\mathrm{P}_{2}$ sobre a resposta de cada grupo. 
DOI: http://dx.doi.org/10.33238/ReBECEM.2019.v.3.n.2.22623

Figura 14:Resposta RPA do professor $\mathrm{P}_{2}$ à $6^{\circ}(\mathrm{b})$

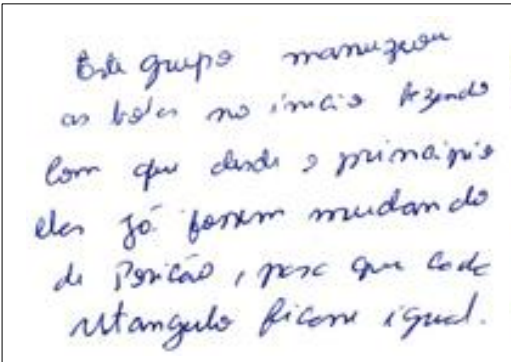

Grupo (1)

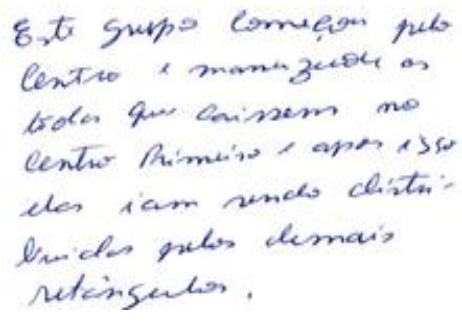

Este surpo comegen puto centro 1 manzzuoles

boles que caissem no

Centro Rimiso a apes asso

elas iam sudes chisti:

lindes sules demais

sutingular.

Grupo (2) ha descide den boles

foi sunds manuzzeds a

dinade pare que elen fonem

dint, as centro, entes de

lhigor as ultimo obroculo

Grupo (3)

(1) [Este grupo manuseou as bolas no início fazendo com que desde o princípio eles já fossem mudando de posição, para cada retângulo ficasse igual.]

(2) [Este grupo começou pelo centro e manuseou as bolas que caíssem no centro primeiro e após isto iam sendo distribuídas pelos demais retângulos.]

(3) [ $\mathrm{Na}$ decida das bolas foi sendo manuseado a descida para que elas fossem direto ao centro, antes de chegar ao último obstáculo.]

Fonte: Dados da pesquisa

Como podemos observar, professor $\mathrm{P}_{2}$ analisa as respostas apresentadas pelos grupos de estudantes e por, provavelmente, não conhecer que o dispositivo de Galton, abordado na questão, obedece a uma Distribuição Normal, diz acreditar na possibilidade do manuseio das bolas para que se formassem tipos diferentes de distribuições. Deste modo, o professor $\mathrm{P}_{2}$, com base nas respostas fornecidas pelos estudantes, apresenta incipientes noções de conhecimento didático envolvendo as facetas cognitiva e afetiva, ou seja, discute razoavelmente como os alunos apresentam seu conhecimento pessoal, suas crenças e atitudes diante do objeto matemático abordado na situação. Além disso, constatamos que a reposta do $\mathrm{P}_{2}$ se assemelha à resposta do professor $\mathrm{P}_{1}$. Deste modo, não foi perceptível, nas respostas apresentadas pelos referidos professores, noções sobre o conhecimento didático interacional e mediacional, o que classifica a resposta de ambos na categoria RPA.

$\mathrm{O}$ professor $\mathrm{P}_{3}$, por sua vez, apresentou um único comentário contemplando as respostas dos três grupos, como podemos observar na figura 14. Deste modo, ele propõe inicialmente que a discussão com a classe de estudantes envolva um teste prático utilizando o dispositivo para saber como se dá a distribuição das bolas. Posteriormente, o professor propõe discussões acerca das respostas de cada grupo e assim, refletir sobre a forma como os estudantes entendem e apreendem a matemática presente nessa questão. Dessa forma, evidenciam-se noções de conhecimento didático envolvendo as facetas 
DOI: http://dx.doi.org/10.33238/ReBECEM.2019.v.3.n.2.22623

mediacional, interacional, cognitiva e afetiva, o que classifica a sua resposta na categoria RA.

Figura 15:Resposta RA do professor $\mathrm{P}_{3}$ à $6^{\circ}(\mathrm{b})^{9}$

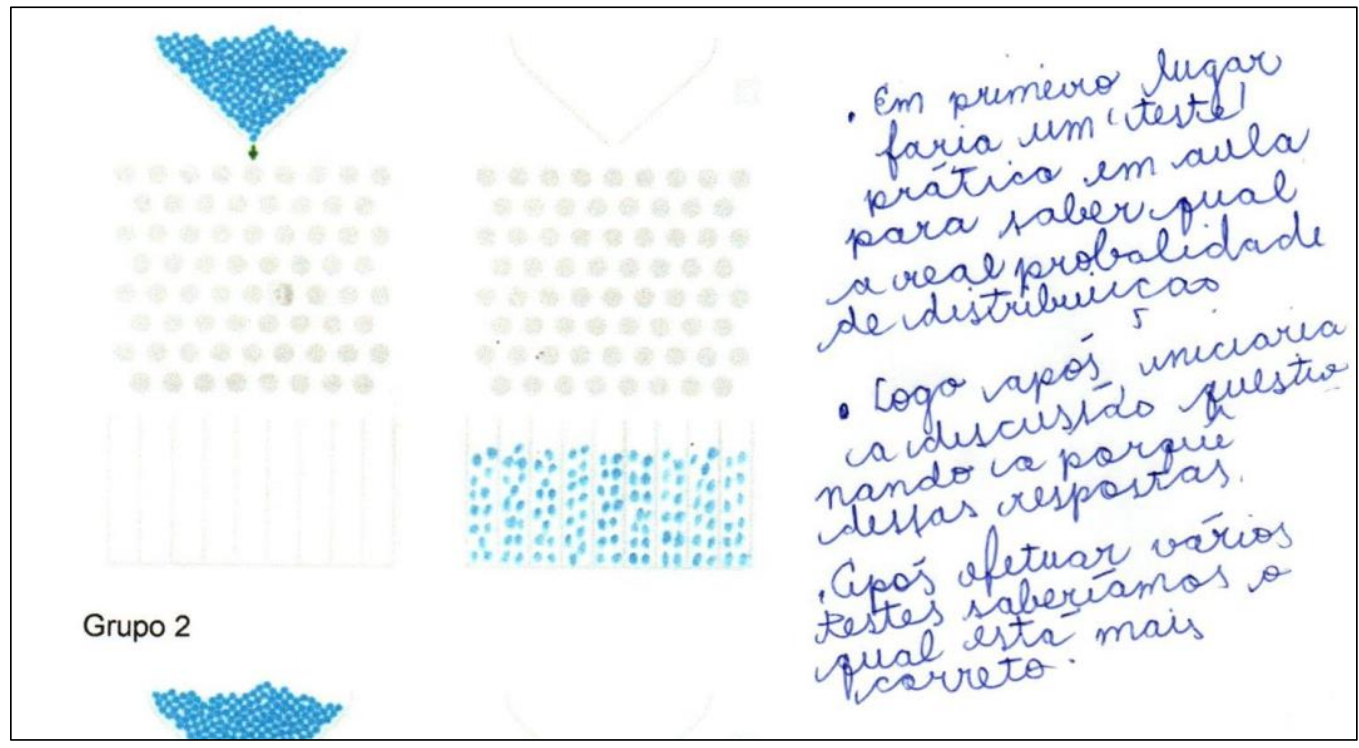

Fonte: Dados da pesquisa

Por fim, após analisarmos as respostas fornecidas pelos três professores participantes do nosso Estudo Piloto, apresentamos, a seguir, uma tabela que resume a classificação das categorias das referidas respostas ao nosso questionário diagnóstico.

Tabela 1: Categorias de respostas dos professores participantes

\begin{tabular}{c|c|c|c|c|c|c|c|c|}
\hline \multicolumn{1}{c|}{ Questões } & $\mathbf{1}^{\mathbf{0}}$ & $\mathbf{2}^{\mathbf{0}}$ & $\mathbf{3}^{\mathbf{0}}$ & $\mathbf{4}^{\mathbf{0}}(\mathbf{a})$ & $\mathbf{4}^{\mathbf{0}}(\mathbf{b})$ & $\mathbf{5}^{\mathbf{0}}$ & $\mathbf{6}^{\mathbf{0}}(\mathbf{a})$ & $\mathbf{6}^{\mathbf{0}}(\mathbf{b})$ \\
\hline Docentes & RPA & RPA & RPA & RI & RPA & RA & RI & RPA \\
\hline $\mathbf{P}_{\mathbf{1}}$ & RPA & RPA & RPA & RI & RPA & RI & RI & RPA \\
\hline $\mathbf{P}_{\mathbf{2}}$ & RPA & RPA & RPA & RI & RPA & RI & RI & RA \\
\hline
\end{tabular}

Fonte: Os Autores

A partir das respostas apresentadas e sintetizadas na tabela, destacamos que os professores $\mathrm{P}_{1}$ e $\mathrm{P}_{2}$, apresentam, cada um, 5 respostas na categoria RPA, dentre as 8 perguntas que compõem o questionário diagnóstico, sendo observado esse tipo de

\footnotetext{
${ }^{9}$ Em primeiro lugar, faria um 'teste' prático em aula para saber qual a real probabilidade de distribuição. Logo após, iniciaria a discussão questionando o porquê dessas respostas. Após efetuar vários testes, saberíamos o qual está mais correto
} 
DOI: http://dx.doi.org/10.33238/ReBECEM.2019.v.3.n.2.22623

categoria para as mesmas questões. Além disso, a categoria RPA foi a mais frequente no desempenho dos três professores.

É possível, ainda, observar que os professores $\mathrm{P}_{2}$ e $\mathrm{P}_{3}$ apresentam os mesmos números de respostas na categoria RI para as mesmas questões e que esse tipo de categoria foi a segunda mais frequente no desempenho dos três professores.

No que diz respeito à categoria RA, ela também pode ser verificada na mesma quantidade para os professores para $\mathrm{P}_{1}$ e $\mathrm{P}_{3}$, isto é, eles apresentam uma resposta classificada nesta categoria, no entanto, em questões distintas. $\mathrm{O}$ professor $\mathrm{P}_{2}$, por sua vez, não apresentou resposta nesse tipo de categorização.

Deste modo, com base na análise das respostas ao questionário diagnóstico, podemos inferir que os três professores participantes desse estudo apresentam desempenhos semelhantes, o que nos faz destacar mais uma vez que é perceptível aos mesmos a presença de lacunas sobre o conhecimento didático-matemático relativo à interrelação entre a Estatística e a Probabilidade por meio da Curva Normal.

\section{Considerações finais}

Partindo do modelo de Conhecimentos e Competências Didático-Matemáticos do professor - CCDM, esse estudo teve por objetivo analisar os conhecimentos didáticomatemáticos de professores de Matemática no Ensino Médio sobre a inter-relação entre a Estatística e a Probabilidade por meio da Curva Normal. No que diz respeito aos dados coletados a partir do questionário diagnóstico, concluímos que, de forma geral, os professores apresentam lacunas sobre os conhecimentos didático-matemáticos necessários para a abordagem desse conceito.

Nesse sentido, quanto ao conhecimento matemático, os participantes demonstraram não conhecer a relação teórica existente entre a Estatística e a Probabilidade. Além disso, o conceito de média demonstrou ser aquele que eles mais conhecem e dominam. Ademais, chamou-nos a atenção o fato de os três professores não conhecerem ou não conseguirem conceituar a Curva Normal, o que pode sinalizar que possivelmente os mesmos não tiverem formação voltada para este conceito.

No entanto, cabe ressaltar que o conhecimento didático envolvendo as facetas mediacional, interacional, cognitiva e afetiva ficou evidenciado em determinadas respostas apresentadas por alguns dos professores. 
DOI: http://dx.doi.org/10.33238/ReBECEM.2019.v.3.n.2.22623

Diante desse quadro, essas conclusões sinalizam que os professores investigados necessitam de um acompanhamento formativo que contemple o estudo sobre a Distribuição Normal, que, como já visto, é classificado com um modelo matemático que abarca conceitos estatísticos e probabilísticos e a inter-relação entre essas áreas de conhecimento. Por fim, acreditamos que esta pesquisa pode promover novas discussões e reflexões sobre o ensino da Estatística e da Probabilidade, ampliando a base de conhecimentos dos professores de Matemática do Ensino Médio relativa aos conceitos estatísticos e probabilísticos abarcados pela Curva Normal, como também, favorecer e potencializar a qualidade das ações docente em sala de aula, em favor da construção do letramento estatístico e probabilístico dos estudantes.

\section{Referências}

AZEVEDO, P. Introdução à Estatística. 3. ed. Natal: Editora Edufrn, 2016.

BAYER, A. et al. Preparação do formando em Matemática-licenciatura plena para lecionar Estatística no Ensino Fundamental e Médio. In: ENCONTRO NACIONAL DE PESQUISA EM EDUCAÇÃO EM CIÊNCIAS, 5., 2005, Bauru. Anais... Bauru: Editora Abrapec, 2005.

BATANERO, C.; DÍAZ, C. Training Teachers to Teach Statistics: what can we learn from research? Statistique et Enseignement, Paris, v. 1, n. 1, p. 5-20, apr. 2010.

BRASIL. Ministério da Educação e da Secretaria de Educação. Base Nacional Curricular Comum. Brasília, 2017.

BRASIL. Ministério da Educação e da Secretaria de Educação. Base Nacional Curricular Comum. Brasília, 2018.

CAZORLA, I.; SANTANA, E. Tratamento da informação para o ensino fundamental e médio. 1. ed. Itabuna: ViaLitterarum, 2006.

CARVALHO, J. I. F. Um estudo sobre os conhecimentos didáticos-matemáticos de probabilidade com professores de matemática dos anos finais do ensino fundamental. 2017. Tese (Doutorado em Educação Matemática) - Universidade Anhanguera de São Paulo, São Paulo, 2017.

FONT, V. Competencias profesionales en la formación inicial de profesores de matemáticas de secundaria. Revista Iberoamericana de Educación Matemática, San Cristóbal de La Laguna, v.1, n. 26, p. 9-25, jun. 2011.

GODINO, J. D., BATANERO, C. Significado institucional y personal de los objetos

Matemáticos. Recherchesen Didactique dês Mathématiques, Granada, v. 14, n.3, p. 325-355, 1994.

GODINO J. D. Categorías de análisis de los conocimientos del profesor de matemáticas.

Revista Iberoamericana de Educación Matemática, San Cristóbal de La Laguna, v.1 n. 20, p. 13-31, Dezembro 2009. 
GODINO, J. D. Origen y aportaciones de la perspectiva ontosemiótica de investigación en didáctica de la matemática. In: SEMINARIO DE INVESTIGACIÓN. INVESTIGACIÓN EN EDUCACIÓN MATEMÁTICA, 16., 2012, Baeza. Anais... Granada, Ediciones Blanca, 2012, p. $49-68$.

GODINO, J. D. et al. Articulando conocimientos y competências del profesor de matemáticas: el modelo CCDM. In: SEMINARIO DE INVESTIGACIÓN EN EDUCACIÓN MATEMÁTICA, 20., 2016, Málaga. Anais... Málaga: SIEM, 2016. p. 285-294.

GONÇALVES, P. Uma abordagem da distribuição normal através da resolução de uma situação problema com a utilização do software geogebra. 2014. Dissertação (Mestrado Profissional em Matemática) - Instituto de Matemática e Estatística, Universidade Federal de Goiás, Goiana, 2014.

GUIMARÃES, G. et al. A educação estatística na educação infantil e nos anos iniciais. Revista Zetetiké, Campinas, v. 17, n. 32, p. 11-28, jul./dez. 2009.

LOPES, C. O ensino da estatística e da probabilidade na educação básica e a formação dos professores, Cadernos Cedes, Campinas, v. 28, n. 74, p. 57-73, jan./abr. 2008.

LOPES, J. M.; TEODORO, J. V.; REZENDE, J. C. Uma proposta para o estudo de probabilidade no Ensino Médio. Zetetike, Campinas, v. 19, n. 36, p. 75-93, jul./dez. 2011.

LIMA, O. A. Distribuição Normal: Uma introdução voltada ao Ensino Médio por simulações via planilha eletrônica e exercícios interativos. 2009. Dissertação (Mestrado Profissional em Ensino de Matemática) - Pontifícia Universidade Católica de São Paulo, São Paulo, 2009.

MACEDO, R. C. Conhecimentos de professores de matemática sobre o processo de ensino e de aprendizagem de noções estatísticas- curva normal. 2016. Dissertação (Mestrado em Educação Matemática) - Universidade Anhanguera de São Paulo, São Paulo, 2016.

MARTINS, G. E. Desvio padrão amostral. Revista de Ciência Elementar, Lisboa, v.1, n.1, p. 1, out./dez. 2013.

OLIVEIRA, M. M. Como fazer projetos, relatórios, monografias, dissertaçõese teses. 5. ed. Rio de Janeiro: editora Elsevier, 2011.

PINO-FAN, L.; GODINO, J. D. Perspectiva ampliada Del conocimiento didáctico-matemático Del profesor. Paradigma, Osomo, v.36, n. 1, p. 87-109, jun. 2015.

SANTANA, M. S. Traduzindo Pensamento e Letramento Estatístico em Atividades para Sala de Aula: construção de um produto educacional, Bolema, Rio Claro, v. 30, n. 56, p. 1165 - 1187, Dezembro, 2016.

SILVA, C. R. Da teoria à prática: uma proposta pedagógica para o ensino da estatística nos anos finais do ensino fundamental. Trabalho de conclusão de curso (Licenciatura em Matemática) - Instituto de Matemática, Estatística e Física, Universidade Federal do Rio Grande, Rio Grande, 2015

PERNAMBUCO. Secretaria de Educação.Parâmetros para a Educação Básica do Estado de Pernambuco, Parâmetros na sala de aula Matemática para o Ensino Fundamental e Médio. Recife, 2013. 
DOI: http://dx.doi.org/10.33238/ReBECEM.2019.v.3.n.2.22623

TAUBER, L. La Construccióndel Significado de La Distribución Normal a partir de

Actividades de Análisis de Datos. 2001. Tese (Doutorado em Educação Matemática) -

Universidad de Servilla, Servilla, 2001.

VERGNAUD, G. A teoria dos Campos Conceituais. In: SEMINÁRIO INTERNACIONAL DE EDUCAÇÃO MATEMÁTICA, 1., 1993, Rio de janeiro. Anais... Rio de Janeiro: Nasser, 1993. p. 1-26.

Recebido em: 15 de junho de 2019.

Aceito em: 05 de agosto de 2019. 